\title{
Rice growth vegetation index 2 for improving estimation of rice plant phenology in costal ecosystems
}

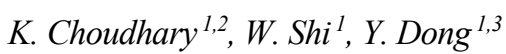 \\ ${ }^{I}$ Department of Land Surveying and Geo-informatics, Smart Cities Research Institute, \\ The Hong Kong Polytechnic University, Hong Kong, \\ ${ }^{2}$ Samara National Research University, Moskovskoye Shosse 34, Samara, 443086, Russia, \\ ${ }^{3}$ Institute of Geophysics \& Geomatics, China University of Geoscience, Wuhan, PR China
}

\begin{abstract}
Crop growth is one of the most important parameters of a crop and its knowledge before harvest is essential to help farmers, scientists, governments and agribusiness. This paper provides a novel demonstration of the use of freely available Sentinel-2 data to estimate rice crop growth in a single year. Sentinel 2 data provides frequent and consistent information to facilitate coastal monitoring from field scales. The aims of this study were to modify the rice growth vegetation index to improve rice growth phenology in the coastal areas. The rice growth vegetation index 2 is the best vegetation index, compared with 11 vegetation indices, plant height and biomass. The results demonstrate that the coefficient of rice growth vegetation index 2 was 0.83 , has the highest correlation with plant height. Rice growth vegetation index 2 is more appropriate for enhancing and obtaining rice phenology information. This study analyses the best spectral vegetation indices for estimating rice growth.

Keywords: crop growth, spectral indices, phenology, rice growth vegetation index 2.

Citation: Choudhary K, Shi W, Dong Y. Rice growth vegetation index 2 for improving estimation of rice plant phenology in costal ecosystems. Computer Optics 2021; 45(3): 438-448. DOI: 10.18287/2412-6179-CO-827.

Acknowledgments: This work is supported by the Hong Kong PhD scholarship from PolyU and research grants from the Research Grants Council of (HKSAR) grant project codes B-Q49D and 1-ZVE8. Authors would also like to acknowledge the support drawn from the Agriculture department of Guangdong, China.
\end{abstract}

\section{Introduction}

Rice (Oryza sativa) is a major essential food for approximately $50 \%$ of the world's population and China around $28 \%$ of global rice production [1]. It is most extensively consumed in Asia and Africa. Rice agriculture is deliberated as an important sector to sustain the national economy [2]. Chinese government strategy emphasizes ameliorate rice yields through techniques for evolving plant growths (using fertilization and irrigation) for food security and sustainability [3]. Effective monitoring and improved agricultural practice are important in China [4, 5], but there is a major challenge to generate and accurate local information. In particular, understanding the dynamics of specific phenological stages of rice to inform strategic and management practices is important [6, 7]. It is accredited as a dominant index for estimate phenological events of crop growth $[8,9]$. Southern China has substantial light and temperature resources that are suitable for dual rice production systems $[10,11]$.

Vegetation Indices (VIs) access from remote sensing based canopies are effective algorithms for quantitative and qualitative estimations of vegetation cover and growth phenology [12]. Numerous, vegetation indices published but few of them are consequential for crop monitoring [13]. The cropland mapping can confer basically essential material for all crop monitoring applica- tions [14]. The time series exploration conveys an appropriate tool to distinguish phenology on a pixel basis [15]. The main purpose of VIs is to expansion the vegetation gesture while decreasing the effects of solar radiation and soil background [16]. Subsequently, NDVI is used as the most essential algorithm for analyzing the spatial distribution of vegetation in the last two decades [17]. The NDVI is determined as the combination of $\left(R_{N I R}-R_{R E D}\right) /\left(R_{N I R}+R_{R E D}\right)$. Huang et al. (2010) [18] have demonstrated that NDVI is an exceptional appraisal of light interception by canopies since they are saturated during the season.

The Green Index (GI) can be determined by the consolidation of red and green bands, which is sensitive for plant chlorophyll [19]. The soil-adjusted vegetation index (SAVI) has conferred for soil background, it is illustrated as $\mathrm{SAVI}=\left(\mathrm{R}_{\mathrm{NIR}}-\mathrm{R}_{\mathrm{RED}}\right)(1+\mathrm{L}) /\left(\mathrm{R}_{\mathrm{NIR}}+\mathrm{R}_{\mathrm{RED}}+\mathrm{L}\right) \quad$ [20]. The enhanced vegetation index (EVI) was described to optimize of leaf area index signal. The EVI is the reflectance of the blue band in the electromagnetic radiations to assist to separate soil from vegetation.

The crop information obtaining through traditional methods, such as ground surveys and sampling are timeconsuming and costly [21]. Numerous studies using timeseries data, acquired from sensors such as MODIS, SPOTVGT, Rapideye have been successfully accompanied for regional monitoring of crop phenology [22, 23]. The Sentinel-2A planetarium was launched on 23 June 
2015 and Sentinel-2B on 7 March 2017 advantageous to simultaneously map the rice field over a large region, due to the spatiotemporal resolution and the repetition frequency. Sentinel-2 has a 5 day revisit cycle with high resolution, which is appropriate for crop mapping at field level. The Sentinel-2 improved spatial and temporal resolution that is beneficial for farmers and academic researchers focusing on agricultural development [24, 25, 26]. The China agriculture field sizes are typically less than 1 hectare, so high spatial resolution acquaintance is essential for evaluating crop information for decisionmaking.

In this paper, we modify a rice growth vegetation index to improve rice plant phenology monitoring in coastal ecosystems using Sentinel-2 data time-series. The newly modified rice growth vegetation index 2 (RGVI2) uses the spectral reflectance of red, NIR, and SWIR bands to discriminate between the green vegetation and background signal. The findings in form of quantitative and spatial information on rice growth at the field level could be valuable to agronomists to timely address issues of food security. This study aims to explain RGVI2 with different VIs relationships derived from reflectance of crops and to compare with different growth parameters such as; plant height and biomass factors which are very important for crop growth monitoring.

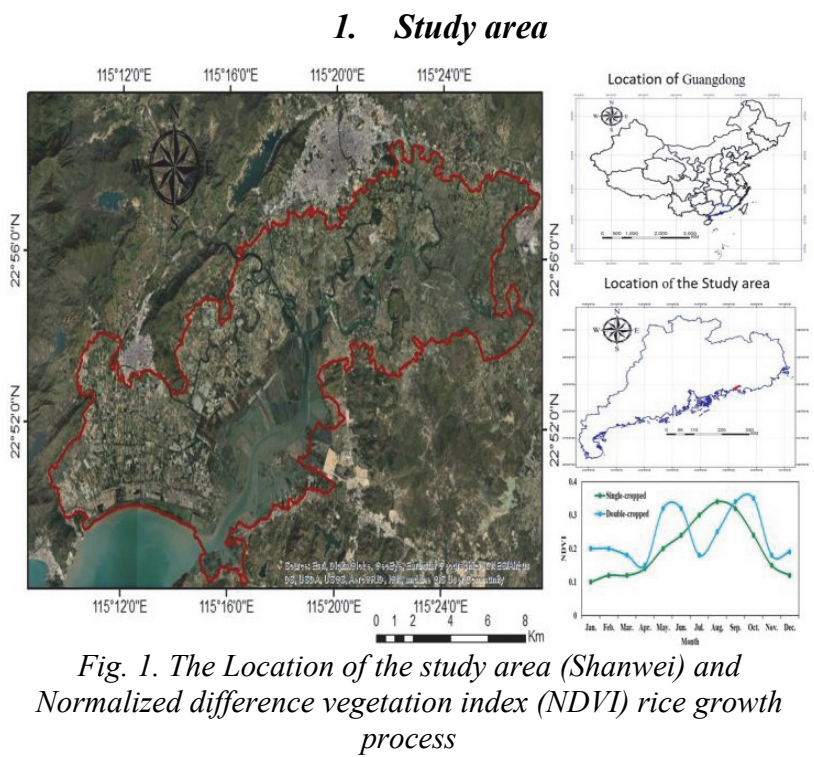

The study area selects Shanwei, the city of Guangdong province, China, which is positioned between latitudes $22^{\circ} 50^{\prime} 0^{\prime \prime}$ to $23^{\circ} 07^{\prime} 55^{\prime \prime} \mathrm{N}$ and longitudes $115^{\circ} 10^{\prime} 0^{\prime \prime}$ to $115^{\circ} 27^{\prime} 30^{\prime \prime} \mathrm{E}$ (Fig. 1). For this research, the total area of $244 \mathrm{~km}^{2}$ selected. The topography of the study area is comparatively flat and its mean terrain elevation is $8 \mathrm{~m}$. The study area is considered by a humid subtropical monsoon climate with the warm season, plentiful precipitation, sufficient sunshine, long frost period, and maritime monsoon characteristics [27]. The mean annual precipitation is $1891 \mathrm{~mm}$, with $80 \%$ occurring during the monsoon season. Precipitation in the rainy season ranging from May to August accounted for over $80 \%$ of the annual total. The temperature ranges from $15.2{ }^{\circ} \mathrm{C}$ in January to $28.3^{\circ} \mathrm{C}$ in July, and the annual mean is $22.60^{\circ} \mathrm{C}$.

The image covers most of Haifeng County and some parts of Chengqu district. The main productions have been rubber, corn, cotton, groundnut, rapeseed, rice, wheat, soybean, fruits and animal husbandry. The rice is the main production in the study region. The soil type is red, which has a low capacity for water storage. The rice growing time period comparatively: Early rice (MarchJuly) and late rice (June-November). This research work was focused on the early rice season (March-July).

\section{Materials and methods 2.1. Data and processing}

To exclusive VIs for rice crop growth mapping, we selected Sentinel-2 data with an acquisition date from January to December. We choose 25 sites for phenology calculation in the study area. The Copernicus, led by the ESA, is one of the most significant Earth observation programs that is focused on the detection and assessment of vegetation. Sentinel-2 data have numerous ways to freely download; one of them is through Copernicus (https://scihub.copernicus.eu/dhus/\#/home) and another United States Geological Survey (USGS) (https://earthexplorer.usgs.gov/). The ArcGIS software is applied for all analyses of work. The radiometric calibration is the most accurate processing for remote sensing data [28]. We used radiometric and geometric correction to improve the image. The Sentinel-2 has three different spatial resolution $10 \mathrm{~m}, 20 \mathrm{~m}$, and $30 \mathrm{~m}$, so all the images were resampled at $10 \mathrm{~m}$ spatial resolution. All vegetation indices were generated for tracking crop health conditions in all growth stages. The crop data (plant height and biomass) were obtained from the website of the Ministry of Agriculture of China (http://english.moa.gov.cn/datastatistics/) and http://www.ricehub.org/RT/varieties/variety-trials/module-3data-collection/. The rice yield data obtained from (http://www.stats.gov.cn/tjsj/ndsj/). It demonstrates that as plant height increased, the reflectance of the near-infrared band steadily increased.

\subsection{ECOSTRESS spectral library data}

Selection of the correct wavelengths and bandwidths are important for rice phenology monitoring. In this study, Sentinel 2 spectral bands, centers and widths in the visible, near-infrared and shortwave infrared spectra were examined for rice crop phenology characteristics using ECOSTRESS library. The chlorophyll pigments present in green leaves strongly absorbs in the visible region of the spectrum, especially in the blue and red wavelengths. The near-infrared (NIR) leaves demonstrate high reflectance values, frequently related to leaf structural properties and biomass. The SWIR, from approximately 1300 to $2500 \mathrm{~nm}$, has good absorption of radiation conquered by water. In agriculture circumstances where crops interrelate with any accustomed aspect of their environment 
(seasonal climatic differences, meteorological events, soil properties, etc.) the interactions between plants and light reflectance translate into changes in plant signal patterns that can be interpreted using satellite data. The mostly spectral ranges used of vegetation are red and near infrared because they accommodate around $90 \%$ of the information relating to vegetation. Thus, vegetation covers can be measuring the difference between the two spectral bands that is the basis of a VIs [29].

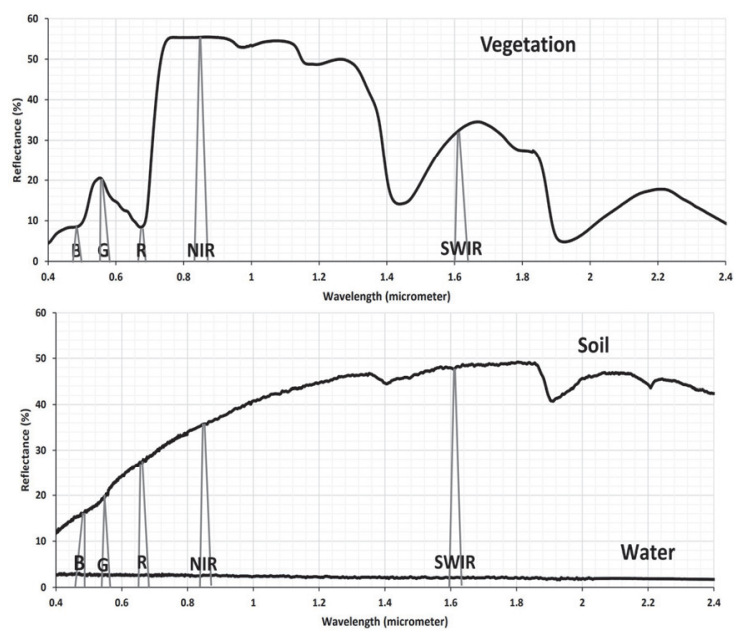

Fig. 2. Spectral reflectance curve of vegetation, soil and water obtain from the Eco-stress spectral library

\subsection{Calculation between rice spectral and rice age}

All acquisition dates of the Sentinel-2 images were taken randomly in the twenty-five field observation sites. The relationship between rice age and rice spectral was completed from spectral of Sentinel-2 and vegetation index with the following equation, which is developed by Nuarsa [30]:

$$
\begin{aligned}
& y=f(X), \\
& R^{2}=1-\frac{\left.\sum y-\bar{y}^{\prime}\right)^{2}}{\left.\sum y-y^{\prime}\right)^{2}}, \\
& S E=1-\frac{\left.\sum y-y^{\prime}\right)^{2}}{n} .
\end{aligned}
$$

Where $y$ is the rice age and $x$ is the rice spectral. The relationship between rice age and spectral was calculated using statistical parameters and standard error of estimation [30]. The water environment plays an important role in rice spectral. The blue band of Sentinel-2 has a good sensitivity with water. Hence, the development of a rice growth vegetation index (RGVI) by Nurasa (2011) used blue, red, NIR, SWIR1 and SWIR2 bands with the following equation:

$$
\mathrm{RGVI}=1-\frac{(R 500+R 687)}{(R 927+R 1662+R 2130)} .
$$

\subsection{Rice growth vegetation index 2 (RGVI2)}

In agriculture conditions where crops interact with the environment (climatic differences, meteorological differ- ences, soil properties, etc.), there is intervention between plants and light reflectance in plant signal configurations that can be estimated using satellite data. We extract VIs values after calculated reflectance values of green, red, NIR, SWIR1, and SWIR2 bands of a single-pixel comparable. This research is established on coastal area rice monitoring so due to climatic discrepancies, SWIR 2 band does not provide appropriate information about rice phenology because it is sensitive to leaf water content and unfortunately it may not capture the phenology timing in coastal ecosystems. So we modified RGVI VIs into RGVI2. The shortwave infrared 2 is a mix-up between rice and water, hence, an improvement in the index is essential and the RGVI is modified here to overcome this problem. It is essentially applied in the analysis of crop growth, desertification research, and rice yield estimation. The equation of rice growth vegetation index 2 is following:

$$
\text { RGVI2 }=1.05-\frac{(R 500+R 687)}{(R 927+R 1662+\alpha)} .
$$

Where $\alpha$ is a weight factor ranges from 0.0 to 1.0 , depending on the spectral configuration of satellite sensors. In practical applications, the values of $\alpha$ are determined according to the specific environmental conditions. After validation procedures, a coefficient value of $\alpha=0.5$ appears to be generally effective for the RGVI2 calculations. The value of $\alpha$ is around 0.5 under the most common environmental conditions. The RGVI2 was proposed to obtain high contrast between rice growth and backgrounds, as well as to minimize the differences among the backgrounds. It is therefore expected to be insensitive to the effects of atmospheric effects in rice phenology monitoring. So we add 0.05 values to improve plant phenology. These values can be simply computed using the central wavelengths of satellite sensors. These results are reliable with the fact that in the visible bands, light is absorbed by leaf pigments, while radiation in the near-infrared is highly reflected by the internal cellular structure of plant leaves [31].

\subsection{Vegetation indices}

A significant selection of vegetation indices, derived from remote sensing data, usually characterizes the crop growth pattern. The main determination was to improve a rice crop growth vegetation index which gives quantitative results of plant growth. The RGVI vegetation index was evaluated for rice growth. The vegetation indices and spectral wavelength applied in this analysis are described in table 1. All VIs mean values and regression models are applied for different vegetation phenomena identification. The selected VIs analyses were conducted into five stages of rice plant growth. This research work used 25 sample plots that have similar vegetation structures. The higher values illustrate a broad spreading of the data points.

\section{Results}

This section demonstrates the time series analysis of VIs and illuminate with different phenological stages of rice for several fields. Subsequently, Spatio-temporal im- 
ages of VIs are interpreted and the relationship between $\mid$ plant height and VIs with biomass is evaluated.

Table 1. Different Vegetation Indices (VIs) computed for the study

\begin{tabular}{|c|c|c|c|c|}
\hline Vegetation Index & Abbreviations & Equations & Properties & References \\
\hline $\begin{array}{l}\text { Normalized difference } \\
\text { vegetation index }\end{array}$ & NDVI & (R927-R687)/(R927+R687) & Green Biomass & Thenkabail et al. (2000) \\
\hline Moisture stress index & MSI & R1662 / R927 & Water content & 18Thenkabail et al. (2000) \\
\hline Green Index & GI & R554/R677 & Green Biomass & Zarco-Tejada et al. (1999) \\
\hline Ratio Vegetation Index & RVI & $\mathrm{R} 927 \mathrm{~nm} / \mathrm{R} 687 \mathrm{~nm}$ & Light use Efficiency & Thenkabail et al. (2000) \\
\hline $\begin{array}{l}\text { Plant senescence } \\
\text { reflectance index }\end{array}$ & PSRI & $\mathrm{R}(680-500) / \mathrm{R} 750$ & Carotenoid pigments & Sims and Gamon (2002) \\
\hline \begin{tabular}{|l|} 
Leaf chlorophyll index \\
\end{tabular} & LCI & $(\mathrm{R} 850-\mathrm{R} 710) /(\mathrm{R} 850+\mathrm{R} 680)$ & Chlorophyll presence & Thenkabail et al. (2000) \\
\hline $\begin{array}{l}\text { Enhanced vegetation } \\
\text { index2 }\end{array}$ & EVI2 & $2.4(\mathrm{R} 800-\mathrm{R} 670) /(\mathrm{R} 800+\mathrm{R} 670+1)$ & LAI & Huete et al. (2002) \\
\hline $\begin{array}{l}\text { Green Ratio vegetation } \\
\text { Index }\end{array}$ & GRVI & R800/R554 & Leaf pigments & Sripada et al. (2006) \\
\hline $\begin{array}{l}\text { Soil adjusted } \\
\text { vegetation index }\end{array}$ & SAVI & $\begin{array}{c}(\mathrm{R} 800-\mathrm{R} 670) /(\mathrm{R} 800+\mathrm{R} 670+\mathrm{L}) \\
*(1+\mathrm{L})\end{array}$ & $\begin{array}{c}\text { Vegetation Canopy / soil } \\
\text { brightness }\end{array}$ & Huete et al. (1988) \\
\hline \begin{tabular}{|l|}
$\begin{array}{l}\text { Normalized differential } \\
\text { greenness Index }\end{array}$ \\
\end{tabular} & NDGI & $\begin{array}{c}0.65 * \mathrm{R} 554+0.35 * \mathrm{R} 800- \\
\mathrm{R} 670 / 0.65 * \mathrm{R} 554+0.35 * \mathrm{R} 800+\mathrm{R} 670\end{array}$ & $\begin{array}{c}\text { Soil brightness, snow and } \\
\text { grass }\end{array}$ & Wei et al. (2019) \\
\hline $\begin{array}{l}\text { Rice Growth } \\
\text { Vegetation Index }\end{array}$ & RGVI & $\begin{array}{c}1- \\
(\mathrm{R} 500+\mathrm{R} 687) /(\mathrm{R} 927+\mathrm{R} 1662+\mathrm{R} 2130)\end{array}$ & Light use Efficiency & Nuarsa et al., (2011) \\
\hline
\end{tabular}

$\boldsymbol{R}$ refer to the reflectance at wavelength

\subsection{Time series analysis of spectral vegetation indices}

Fig. 3 illustrates the consistency between different VIs for each class which was extracted from all the training points. Water is straightforwardly recognized in all VIs. The vegetation values in RGVI2, NDGI, EVI2, and NDVI show a perfect distinction from the crop value. For crops, rice was different from other crops in the GRVI, RVI, SAVI, EVI2 and NDVI. The RGVI2 demonstrates huge differences between rice and other crops. The MSI shows a discrepancy between vegetation and water but less discrepancy between rice and other crops. During the transplanting stage of Early rice (March to July) and Late rice (June to November), water flooding significantly decreased backscatter, which helped to identify rice cropping intensity.

The early rice planted time is mid of March that time NDVI has low values due to soil contribution to the reflectance when there was no crop. The plant started developing at the end of April. So vegetation values also increase during this period. A trend demonstrates VIs rising from May to Jun because of rice plants developed in this period. Rice plant approached full development in July, that's why NDVI values decreased. In July VIs was very low because rice fields were harvested.

Table 2. Regression model $\left(R^{2}\right)$ between different vegetation indices of rice crop

\begin{tabular}{|l|c|c|c|c|c|c|c|c|c|c|c|}
\hline \multicolumn{1}{|c|}{ VIs } & RGVI2 & NDVI & NDGI & MSI & LCI & GRVI & GI & EVI2 & PSRI & RVI & SAVI \\
\hline RGVI2 & 1 & 0.89 & 0.82 & 0.22 & 0.01 & 0.86 & 0.27 & 0.91 & 0.32 & 0.90 & 0.88 \\
\hline NDVI & 0.89 & 1 & 0.90 & 0.12 & 0.00 & 0.90 & 0.30 & 0.91 & 0.41 & 0.90 & 0.90 \\
\hline NDGI & 0.82 & 0.90 & 1 & 0.34 & 0.00 & 0.87 & 0.22 & 0.94 & 0.36 & 0.92 & 0.93 \\
\hline MSI & 0.22 & 0.12 & 0.34 & 1 & 0.00 & 0.25 & 0.01 & 0.29 & 0.06 & 0.31 & 0.30 \\
\hline LCI & 0.01 & 0.00 & 0.00 & 0.00 & 1 & 0.00 & 0.01 & 0.00 & 0.05 & 0.00 & 0.00 \\
\hline GRVI & 0.86 & 0.90 & 0.87 & 0.25 & 0.00 & 1 & 0.44 & 0.83 & 0.58 & 0.96 & 0.81 \\
\hline GI & 0.27 & 0.30 & 0.22 & 0.01 & 0.01 & 0.44 & 1 & 0.17 & 0.27 & 0.39 & 0.13 \\
\hline EVI2 & 0.91 & 0.91 & 0.94 & 0.29 & 0.00 & 0.83 & 0.17 & 1 & 0.26 & 0.90 & 0.96 \\
\hline PSRI & 0.32 & 0.41 & 0.36 & 0.06 & 0.05 & 0.58 & 0.27 & 0.26 & 1 & 0.46 & 0.27 \\
\hline RVI & 0.90 & 0.90 & 0.92 & 0.31 & 0.00 & 0.96 & 0.39 & 0.90 & 0.46 & 1 & 0.87 \\
\hline SAVI & 0.88 & 0.90 & 0.93 & 0.30 & 0.00 & 0.81 & 0.13 & 0.96 & 0.27 & 0.87 & 1 \\
\hline
\end{tabular}

The consequences of selecting VIs are based on the mean value and linear regression hypostasis of the 11 vegetation indices such as NDVI, RGVI2, NDGI, MSI, LCI, GRVI, GI, EVI2, PSRI, RVI, and SAVI (Table 2). The regression analysis $\left(\mathrm{R}^{2}\right)$ showed that strong correla- tion VIs are RGVI2, EVI2, SAVI, and NDVI, such as RGVI2 correlated with SAVI (0.89), EVI2 (0.91); EVI2 correlated with SAVI (0.96), NDGI (0.94); SAVI correlated with EVI2 (0.96), RGVI2 (0.90) and NDVI correlated with EVI2 (0.91), SAVI (0.90), RGVI2 (0.89), 
NDGI (0.90). The GRVI, GI and RVI moderate correlate with other vegetation indices. PSRI and MSI are not well correlated with other VIs. Also, LCI is not correlated with other VIs. Plant senescence reflectance index and Moisture stress index as reflectance was diminished due to wa-
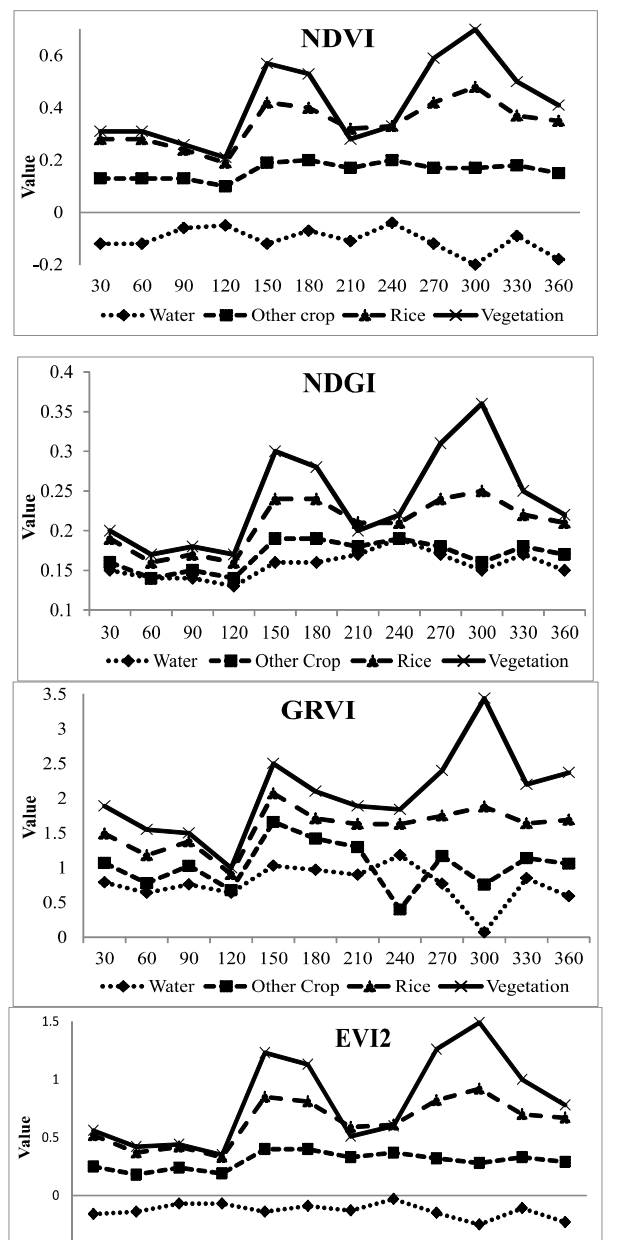

$-0.5$

$\begin{array}{lllllllllll}60 & 90 & 120 & 150 & 180 & 210 & 240 & 270 & 300 & 330 & 360\end{array}$

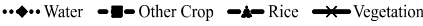

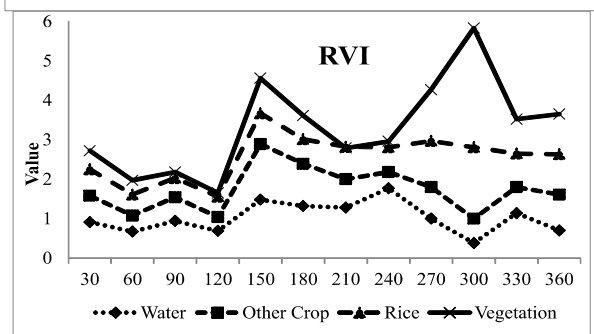

ter content of the plant. There was a clear difference in the Moisture stress index at different stages for rice crops. It indicated that the index is not able to differentiate the effect of water stress. The results of the regression correlation based on the coefficient of determination are as follows:
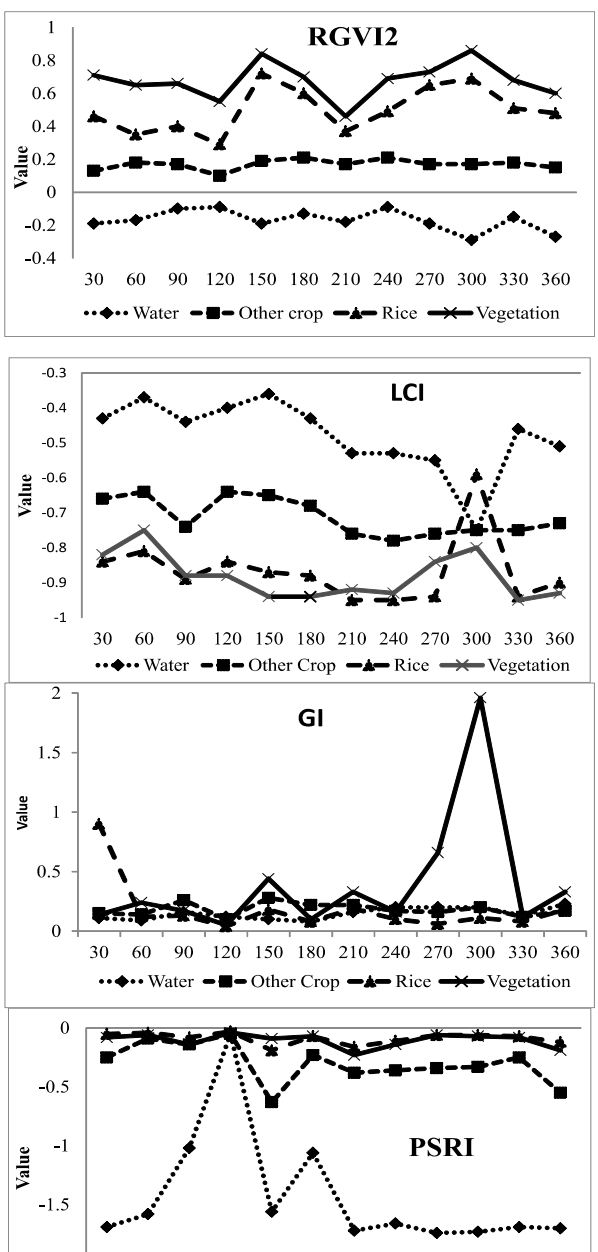

$\begin{array}{llllllllllll}30 & 60 & 90 & 120 & 150 & 180 & 210 & 240 & 270 & 300 & 330 & 360\end{array}$

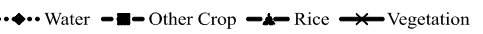

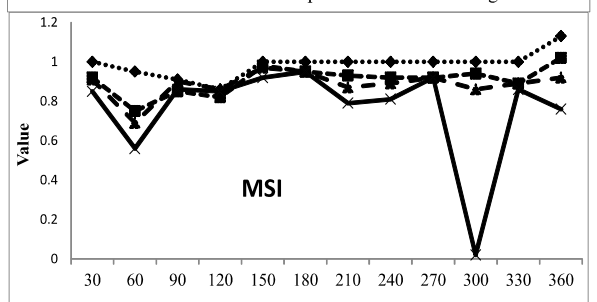

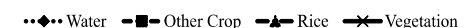

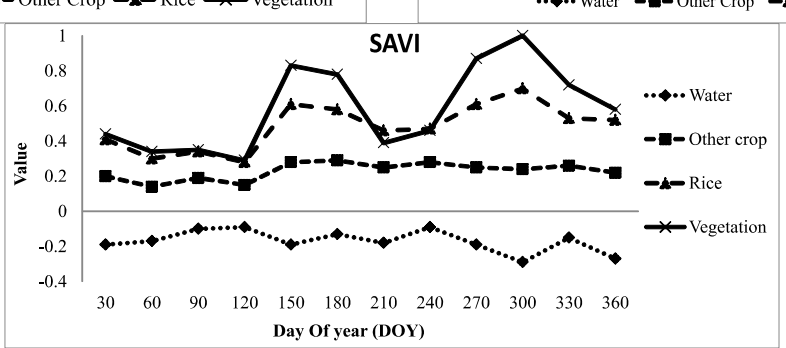

Fig. 3. Time series analysis of spectral vegetation indices for four classes

The results demonstrate that SAVI, RGVI2, NDVI, NDGI and EVI2 provide additional evidence approximately rice crop growth. The RGVI2 values are amazing where the vegetation shield is exposed and the soil surface is low. The MSI values 
are a reflection measurement that is slight to increasing the leaf's water content. The Enhanced vegetation index (EVI2) results illustrate that it has been developed to optimize vegeta-
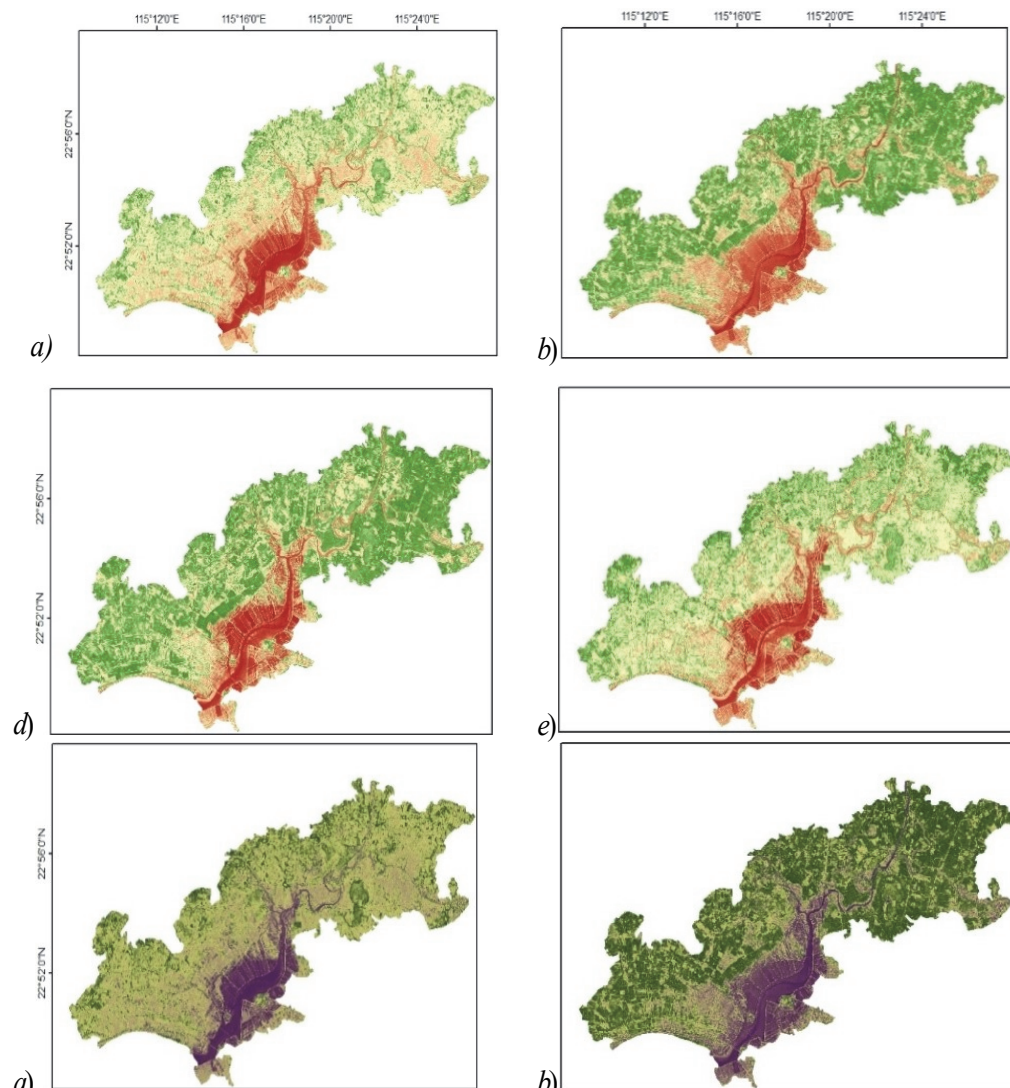

a)
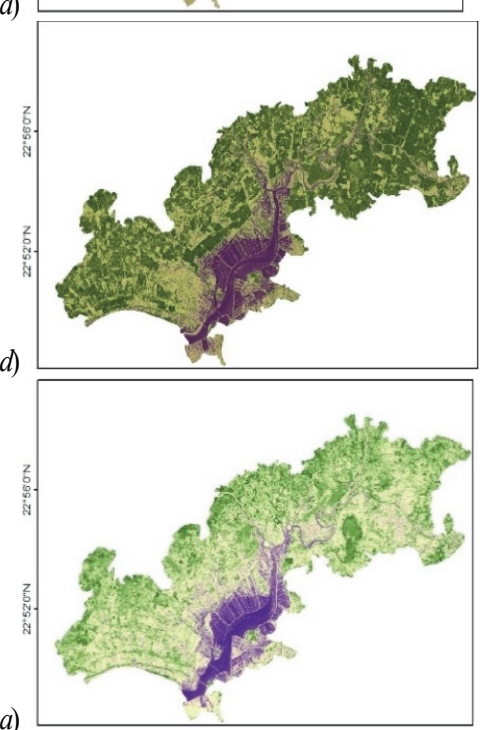

a)

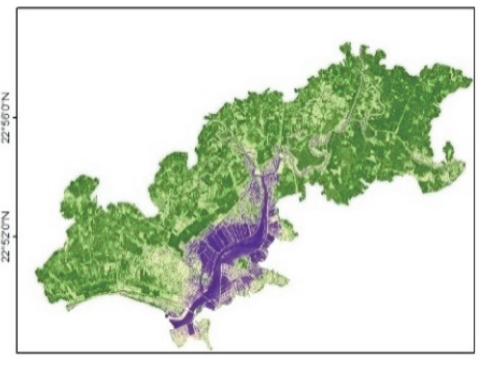

tion signals with better sensitivity in high vegetation areas. NDVI is chlorophyll sensitive, with the EVI2 canopy being more responsible for structural changes $(32,33)$.
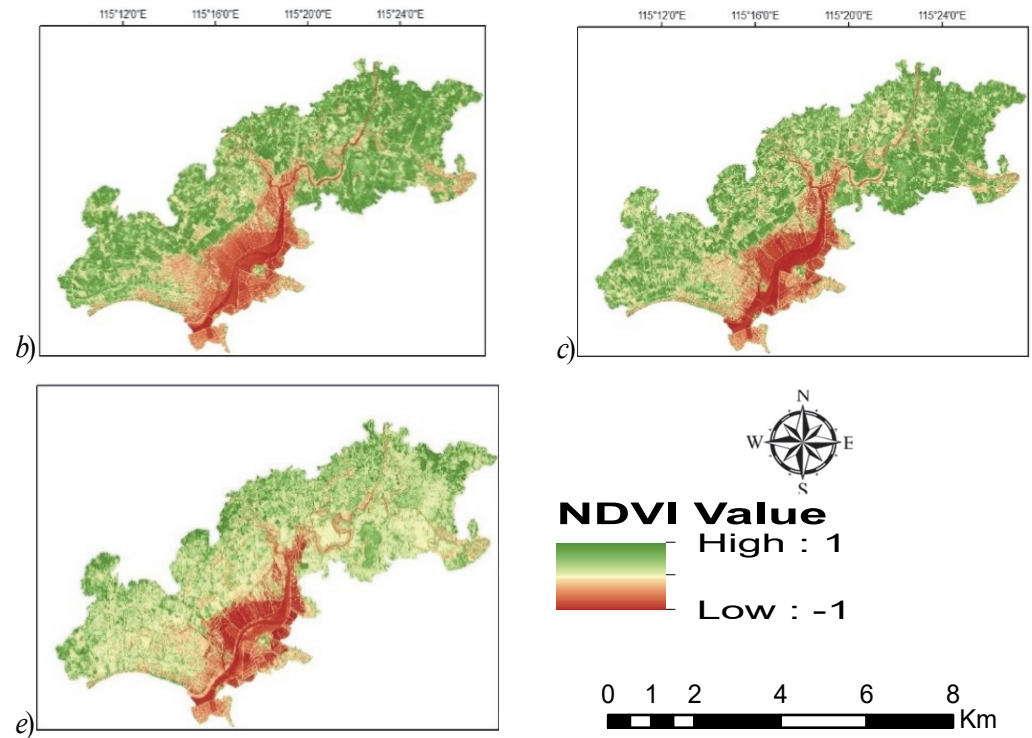

Low : -1
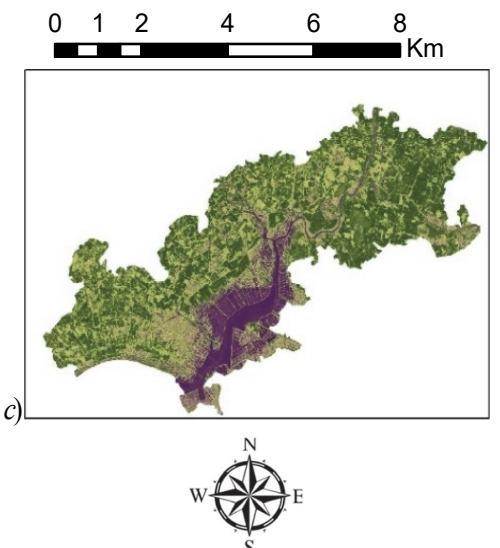

SAVI Value

High: 1.0

Low : 0.0
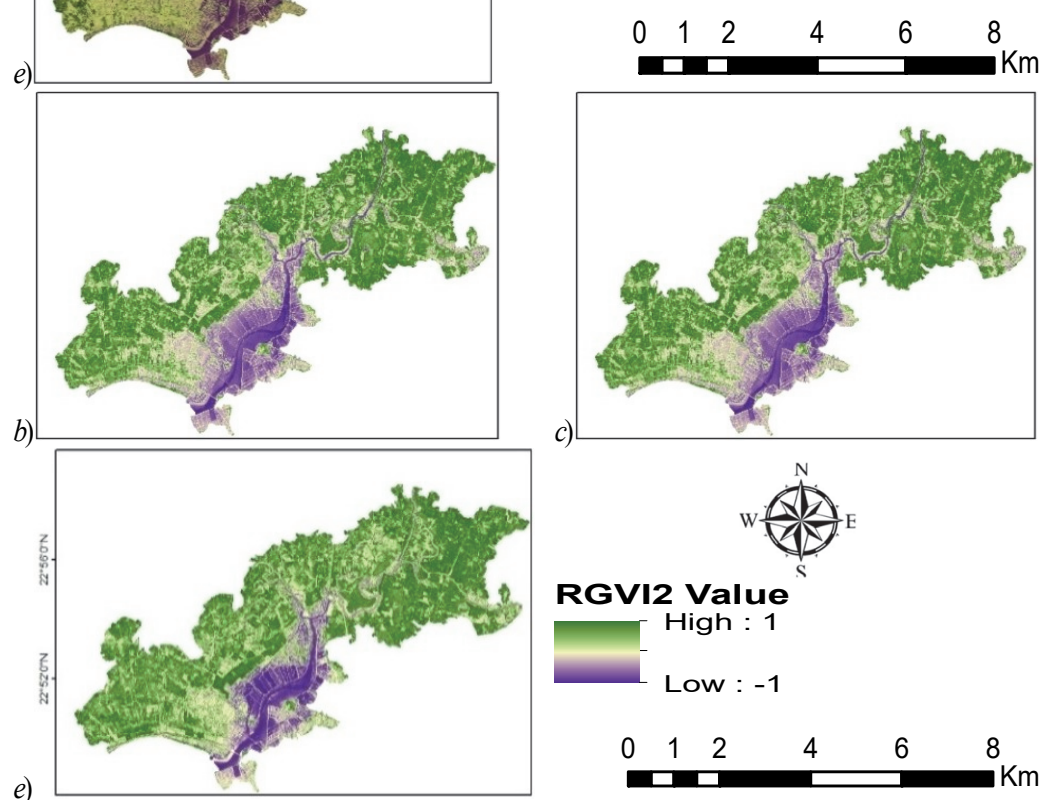

Fig. 4. Spatio-Temporal changes of NDVI, SAVI, and RGVI2 at different phenological stage;

(a) Seeding; (b) Tillering; (c) Jointing (d) Booting; (e) Maturity 


\subsection{Crop monitoring in phenological stage}

Based on literature $[34,35,36]$ the growth of rice crops have been categorized into five stages; seedling, tillering, jointing, booting and maturity (Fig. 4). The seedling and tillering stage (around 65 days) contains the vegetation phase.

The jointing and booting stage (around 30 days) contains the reproductive phase. The maturity stage (around 30 days) contains of ripening phase. Meanwhile the vegetation stage rice elevation increase constantly, later small changes are seen during the reproductive stage. In the ini-
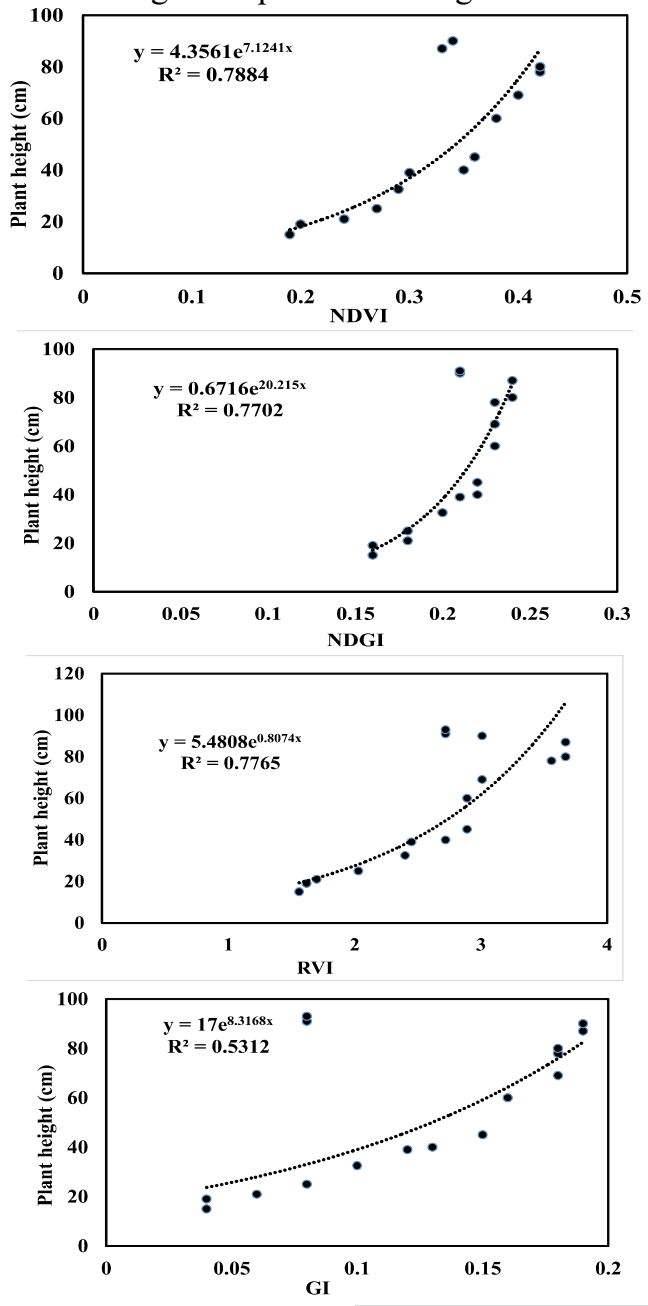

tial stage of crop growth soil visibility is the main reason for a low values, that's why all vegetation indices have low values. During the seedling stage, it increased and reached a peak around the jointing and booting stage formerly it declined towards the maturity of the crop. All these vegetation indices are related to the greenness content of the crops.

These indices recorded at the booting stage were better correlated with crop parameters as compared to other phenological stages. According to Kaur et al. (2015) [37], the correlation between different crop parameters and vegetation indices were best at $75-105$ days (booting).
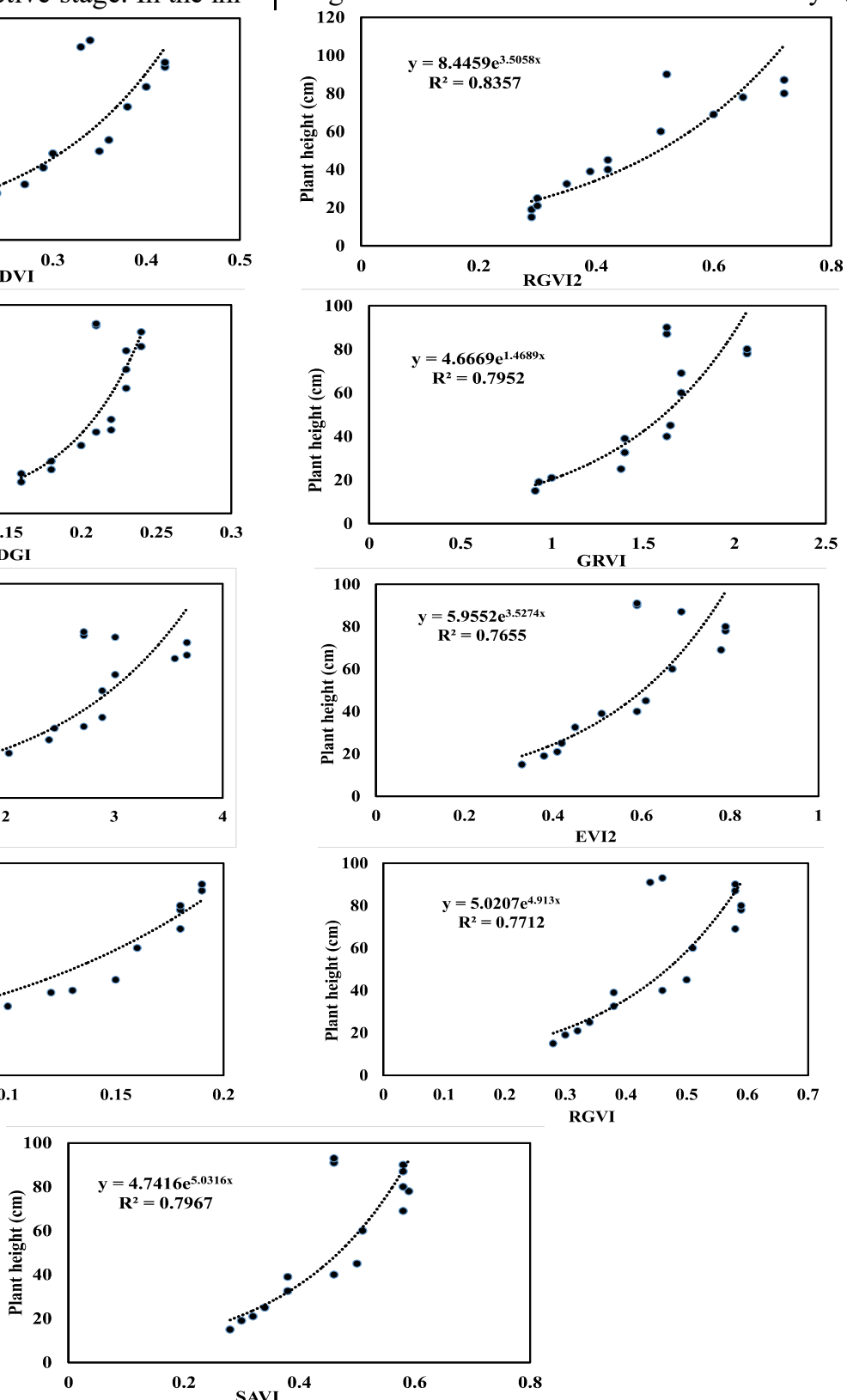

Fig. 5. Statistical analysis of vegetation indices with plant height

Spatial-temporal alterations were occupied in disparate vegetation indices. These indices were derivative visible-near infrared and red bands such as NDVI, GI, RVI, SAVI, RGVI2, EVI2, etc. All maps are beneficial to evaluating variability in crop growth with the pheno- logical stage. This field is dominated by rice and other crops. Though, this research is individually dedicated to rice. The rice growth study is incomplete without the VIs time series. We scrutinized all 11 VIs for crop health monitoring but the best consequences are given 
by RGVI2. The SAVI, NDVI is intermediate VIs. These maps are increased in Plant height as the plant was growing. The vegetation indices designated the con-
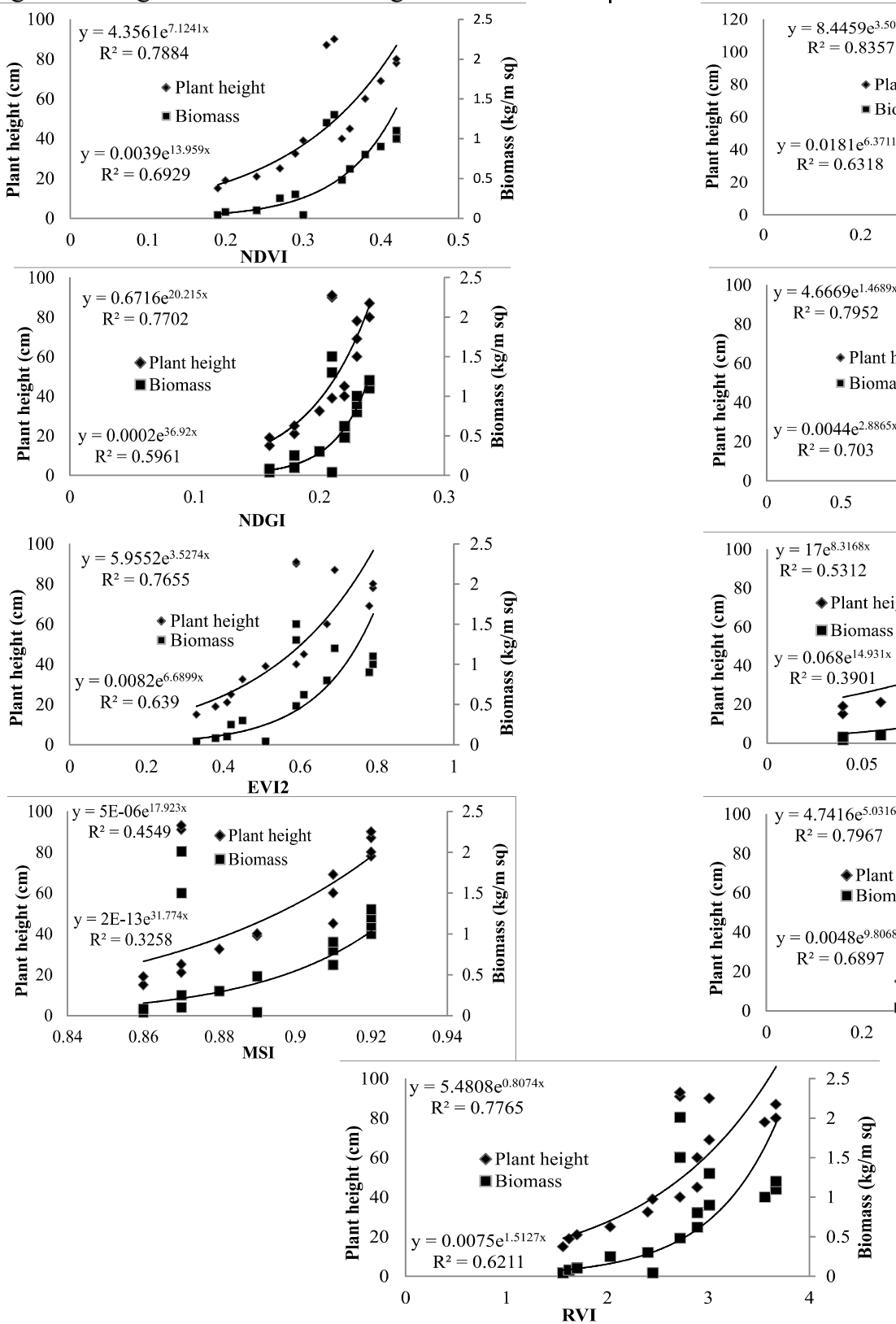

Fig. 6. Regression models between plant growth parameters and spectral vegetation indices

\subsection{Relationship between spectral indices and crop parameters}

The exponential regression analysis was the best estimation to demonstrate the relationship amongst rice plant spectral and rice plant height. All vegetation indices estimated in this study indicated a substantial relationship with rice plant height and biomass. The Rice Growth Vegetation Index 2 (RGVI2) modified in this study gives a better relationship, with $\mathrm{R}^{2}=0.83$, followed by NDVI, SAVI, GRVI, and RVI, with $\mathrm{R}^{2}$ values of $0.78,0.79$, 0.79 , and 0.77 , scientifically. Figure 5 demonstrates that rice plant height and rice spectral have a very good rela- sistency in plant growth. These delineations exhibited that VIs can provide a good delegate for tracking vegetation health status.
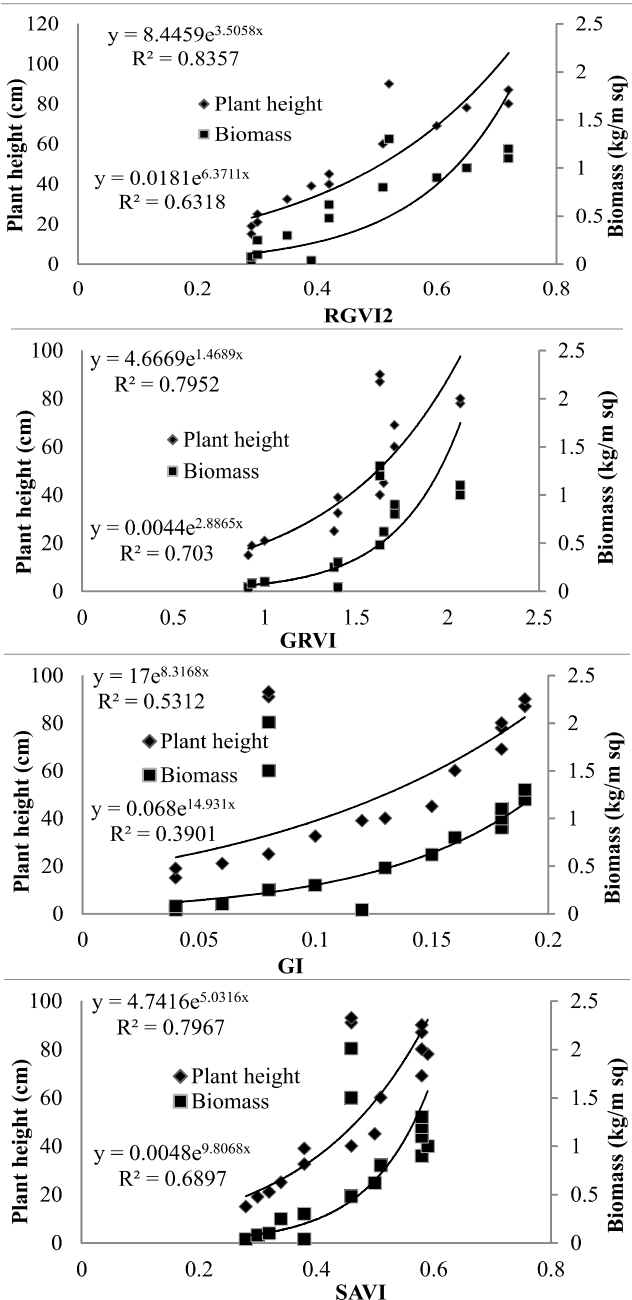

Using multiple bands of Sentinel-2 gave an enhanced relationship between rice plant height and rice spectral than was applying a single band.

Exponential regression analysis between different plant growth parameters and spectral vegetation indices are presented in figure 6 . The GRVI has the highest correlation with biomass. The correlation coefficient of SAVI for biomass was $2.5 \%$ higher as compared to that of EVI2. The high correlation GRVI have the effect of replacing the green band with a red band, as the red band activation of the green band is due to leaf structure. SAVI, RGVI2, and EVI2 have well correlated with biomass. The correlation analysis of plant height and biomass of 
rice was performed to the capability of VIs for rice crop growth. Most of the vegetation indices were positively correlated with both biophysical parameters.

\section{Accuracy}

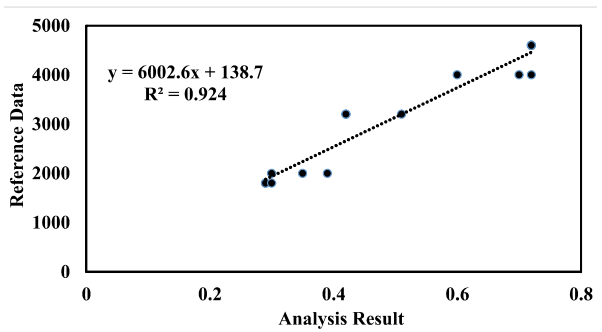

Fig. 7. Linear regression model between RGVI2 and reference data

The sentinel-2 was quantitatively evaluated for rice plant growth by analysis amongst different vegetation indices. The Google Earth Engine was very useful for identifing features during accuracy estimation. The Low estimates for almost all vegetation indices values were compared to the local government data. The mixed pixel can reduce the accuracy of the calculation. Xiao et al. 2019 [38] has approved the same phenomena using MODIS data and results in a demonstration that the estimation of the rice spectral in Southern China was lower than the reference data. The Linear regression model established between RGVI2 spectral indices and reference data (grain yield) of the rice crop is accessible in Fig. 7. The accuracy of the vegetation extraction based on RGVI2 is higher than other visible band-based VIs and G band. Furthermore, the accuracy of RGVI2 has been described to be over $92 \%$. So RGVI2 vegetation indices can be applied in decision support systems for yield forecasting models.

\section{Conclusion}

The RGVI2 index has a mathematical expression based on the reflectance spectra of different components (vegetation, water, soil, etc.). Furthermore, it is simply parameterized by an obvious calculation applying the wavelengths of remote sensing data. The analysis results demonstrated that RGVI2 could eliminate the effects of water on estimates of rice phenology. The RGVI2 is more suitable for the amplification of rice phenology because it can efficiently reduce the water effect. The accuracy of RGVI2 has been reported around 92\%. Different environments have their individual sophisticated characteristics, which requirements to be assumed when using different VIs. All VIs have their specific expression of green vegetation, its own suitability for specific uses. For practical applications, the RGVI indices needs to be modified with attention by comprehensively considering and analyzing the advantages then combine them to be applied in a specific environment. Among training sites, the RGVI2 was superior over the other VIs in estimating rice phenology on coastal areas. The results indicated that time series analysis and the correlation between biophysical parame- ters provide better information for crop growth monitoring. The use of different vegetation indices is required for improved management decisions (39, Shen et al. 2019,). It can help farmers in accurately locating the problem area in their field and run necessary field operations to reduce losses in crop yield. Usually, appropriate climatic circumstances throughout the particular growth stage are critical for rice plant growth and grain yield. Hence, further study to analyze the climate character during specific growth stages related to grain yield in long term experiments is needed. The grain yield will significantly and positively be correlated with the plant height. In future studies, additional evaluations for rice yield will be carried out.

\section{Authorship contribution statement}

Komal Choudhary: Conceptualization, Formal analysis, Methodology, data curation, Writing - original draft. Wenzhong Shi: Supervision, Writing - review \& editing. Yanni Dong: Data curation, Writing - review \& editing.

\section{Declaration of conflicts interest}

We declare that our paper has no conflict of interest among authors and other journals.

\section{References}

[1] Bouman BAM, Van Laar HH. Description and evaluation of the rice growth model ORYZA2000 under nitrogenlimited conditions. Agric Syst 2006; 87(3): 249-273.

[2] Zhou G, Liu X, Liu M. Assimilating remote sensing phenological information into the WOFOST model for rice growth simulation. Remote Sens 2019; 11(3): 268.

[3] Wang F, Wang F, Zhang Y, Hu J, Huang J, Xie J. Rice yield estimation using parcel-level relative spectral variables from uav-based hyperspectral imagery. Front Plant Sci 2019; 10(April): 1-12.

[4] Ministry of Agriculture of the People's Republic of China. 28 April 2012. The 12thFive Year Plan. $<$ http://english.agri.gov.cn/>.

[5] Duncan JMA, Dash J, Atkinson PM. The potential of satellite-observed crop phenology to enhance yield gap assessments in smallholder landscapes. Front Environ Sci 2015; 3(AUG): 1-16.

[6] Singha $\mathrm{M}, \mathrm{Wu} \mathrm{B}$, Zhang $\mathrm{M}$. An object-based paddy rice classification using multi-spectral data and crop phenology in Assam, Northeast India. Remote Sens 2016; 8(6): 479.

[7] Ren S, Chen X, An S. Assessing plant senescence reflectance index-retrieved vegetation phenology and its spatiotemporal response to climate change in the Inner Mongolian Grassland. Int J Biometeorol 2017; 61(4): 601-612.

[8] Choudhary K, Shi W, Boori MS, Corgne S. Agriculture phenology monitoring using NDVI time series based on remote sensing satellites: A case study of Guangdong, China. Optical Memory and Neural Networks 2019; 28(3): 204-214.

[9] Bajocco S, Raparelli E, Teofili T, Bascietto M, Ricotta C. Text mining in remotely sensed phenology studies: A review on research development, main topics, and emerging issues. Remote Sens 2019; 11(23): 2751. 
[10] Jin X, et al. A review of data assimilation of remote sensing and crop models. Eur J Agron 2018; 92(November): 141-152.

[11] Naito $\mathrm{H}$, et al. Estimating rice yield related traits and quantitative trait loci analysis under different nitrogen treatments using a simple tower-based field phenotyping system with modified single-lens reflex cameras. ISPRS J Photogramm Remote Sens 2017; 125: 50-62.

[12] Cui B, Zhao Q, Huang W, Song X, Ye H, Zhou X. A new integrated vegetation index for the estimation of winter wheat leaf chlorophyll content. Remote Sens 2019; 11(8): 1-18.

[13] Boori MS, Choudhary K, Kupriyanov AV. Crop growth monitoring through Sentinel and Landsat data based NDVI time-series. Computer Optics 2020; 44(3): 409-419. DOI: 10.18287/2412-6179-CO-635.

[14] Nellis MD, Price KP, Rundquist D. Remote sensing of cropland agriculture. SAGE Handb Remote Sens 2008: 368-383.

[15] Boschetti M, Stroppiana D, Brivio PA, Bocchi S. Multiyear monitoring of rice crop phenology through time series analysis of MODIS images. Int J Remote Sens 2009; 30(18): 4643-4662.

[16] Prabhakar M, Gopinath KA, Reddy AGK, Thirupathi M, Rao CS. Mapping hailstorm damaged crop area using multispectral satellite data. Egypt J Remote Sens Sp Sci 2019; 22(1): 73-79.

[17] Singha M, Wu B, Zhang M. Object-based paddy rice mapping using $\mathrm{HJ}-1 \mathrm{~A} / \mathrm{B}$ data and temporal features extracted from time series MODIS NDVI data. Sensors (Switzerland) 2017; 17(1): 10.

[18] Huang Q, Zhang L, Wu W, Li D. MODIS-NDVI-based crop growth monitoring in China Agriculture Remote Sensing Monitoring System. $20102^{\text {nd }}$ IITA Int Conf Geosci Remote Sensing (IITA-GRS 2010) 2010; 2: $287-$ 290.

[19] Yu Q, Xiang M, Wu W, Tang H. Changes in global cropland area and cereal production: An inter-country comparison. Agric Ecosyst Environ 2019; 269: 140-147.

[20] Naito $\mathrm{H}$, et al. Estimating rice yield related traits and quantitative trait loci analysis under different nitrogen treatments using a simple tower-based field phenotyping system with modified single-lens reflex cameras. ISPRS J Photogramm Remote Sens 2017; 125: 50-62.

[21] Chen J, Huang J, Hu J. Mapping rice planting areas in southern China using the China Environment Satellite data. Math Comput Model 2011; 54(3-4): 1037-1043.

[22] Guo J, Mao K, Zhao Y, Lu Z, Xiaoping L. Impact of climate on food security in mainland China: A new perspective based on characteristics of major agricultural natural disasters and grain loss. Sustain 2019; 11(3): 1-27.

[23] Onojeghuo AO, Blackburn GA, Huang J, Kindred D, Huang W. Applications of satellite 'hyper-sensing' in Chinese agriculture: Challenges and opportunities. Int $\mathrm{J}$ Appl Earth Obs Geoinf 2018; 64(v): 62-86.

[24] Chemura A, Mutanga O, Dube T. Separability of coffee leaf rust infection levels with machine learning methods at Sentinel-2 MSI spectral resolutions. Precis Agric 2017; 18(5): 859-881.

[25] Escolà A, Badia N, Arnó J, Martínez-Casasnovas JA. Using Sentinel-2 images to implement Precision
Agriculture techniques in large arable fields: First results of a case study. Adv Anim Biosci 2017; 8(2): 377-382.

[26] Pan H, Chen Z, de Allard W, Ren J. Joint assimilation of leaf area index and soil moisture from Sentinel-1 and Sentinel-2 data into the WOFOST model for winter wheat yield estimation. Sensors (Switzerland) 2019; 19(14): 3161.

[27] Li L, Zha Y. Estimating monthly average temperature by remote sensing in China. Adv Sp Res 2019; 63(8): 23452357.

[28] Shen W, Li M, Huang C, He T, Tao X, Wei A. Local land surface temperature change induced by afforestation based on satellite observations in Guangdong plantation forests in China. Agric For Meteorol 2019; 276-277(June): 107641.

[29] Smith B. The emergence of agriculture. New York, NY: WH Freeman and Co; 1994.

[30] Nuarsa IW, Nishio F, Hongo C. Spectral characteristics and mapping of rice plants using multi-temporal Landsat data. J Agric Sci 2011; 3(1).

[31] Yang W, et al. A semi-analytical snow-free vegetation index for improving estimation of plant phenology in tundra and grassland ecosystems. Remote Sens Environ 2019; 228(June): 31-44.

[32] Li L, Friedl MA, Xin Q, Gray J, Pan Y, Frolking S. Mapping crop cycles in China using MODIS-EVI time series. Remote Sens 2014; 6(3): 2473-2493.

[33] Boschetti M, et al. PhenoRice: A method for automatic extraction of spatio-temporal information on rice crops using satellite data time series. Remote Sens Environ 2017; 194: 347-365.

[34] Huang J, Rozelle S. China's 40 years of agricultural development and reform. China's 40 Years Reform Dev 1978-2018 2018; July: 487-506.

[35] Karthikeyan L, Chawla I, Mishra AK. A review of remote sensing applications in agriculture for food security: Crop growth and yield, irrigation, and crop losses. J Hydrol 2020; 586(March): 124905.

[36] Motohka T, Nasahara KN, Oguma H, Tsuchida S. Applicability of Green-Red Vegetation Index for remote sensing of vegetation phenology. Remote Sens 2010; 2(10): 2369-2387.

[37] Kaur R, Singh B, Singh M, Thind SK. Hyperspectral indices, correlation and regression models for estimating growth parameters of wheat genotypes. J Indian Soc Remote Sens 2015; 43(3): 551-558.

[38] Wang J, et al. Field-scale rice yield estimation using sentinel-1A synthetic aperture radar (SAR) data in coastal saline region of Jiangsu Province, China. Remote Sens 2019; 11(19): 1-9.

[39] Agapiou A, Hadjimitsis DG, Sarris A, Georgopoulos A, Alexakis DD. Optimum temporal and spectral window for monitoring crop marks over archaeological remains in the Mediterranean region. J Archaeol Sci 2013; 40(3): 14791492.

[40] Susantoro TM, Wikantika K, Saepuloh A, Harsolumakso $\mathrm{AH}$. Selection of vegetation indices for mapping the sugarcane condition around the oil and gas field of North West Java Basin, Indonesia. IOP Conf Ser Earth Environ Sci 2018; 149(1): 0-1. 


\section{Authors' information}

Komal Choudhary has completed her Bachelors and Master's degree in Geography from the University of Rajasthan, India in the year 2003 and 2005 respectively. She also completed Bachelors of education in 2007 from the University of Rajasthan, India. After her education, she was a college lecturer. She is currently a Ph.D. student in the Land Surveying and Geo-informatics department, Smart Cities Research Institute, The Hong Kong Polytechnic University, Hong Kong. Her current research interest image processing, risk assessment and remote sensing.

E-mail: komal.kumarri@connect.polyu.hk.

Wen-zhong John Shi is Academician of International Eurasian Academy of Sciences, Otto Poon Charitable Foundation Professor in Urban Informatics, Chair Professor in GISci and Remote Sensing, Director of PolyU-Shenzhen Technology and Innovation Research Institute (Futian), Director of Smart Cities Research Institute, Head of Land Surveying and Geo-Informatics department, The Hong Kong Polytechnic University, and Joint Research Laboratory on Spatial Information, The Hong Kong Polytechnic University and Wuhan University. He served as President of Commission II for International Society for Photogrammetry and Remote Sensing (2008-2012) and President for Hong Kong Geographic Information System Association (2001-2003). He also serves as an editorial board member for multiple international journals. He obtained his doctoral degree from University of Osnabrück in Vechta, Germany in 1994. Areas of interest: urban informatics for Smart Cities, GISci and remote sensing, intelligent analytics and quality control for spatial big data, artificial-intelligence-based object extraction and change detection from satellite imagery, and mobile mapping and 3-D modelling based on LiDAR and remote sensing imagery. He has published more than 220 research articles that are indexed by Science Citation Index (SCI) and 15 books. E-mail: lswzshi@polyu.edu.hk.

Yanni Dong (S'14-M'17), received the B.S. degree in Sciences and Techniques of Remote Sensing from Wuhan University, Wuhan, China, in 2012, and the Ph.D. degree in Photogrammetry and Remote Sensing from State Key Lab of Information Engineering in Surveying, Mapping and Remote Sensing, Wuhan University, Wuhan, China, in 2017. She is currently an associate professor with the Institute of Geophysics and Geomatics, China University of Geosciences, Wuhan, China and also a Hong Kong Scholar with the Land Surveying and Geo-Informatics department, The Hong Kong Polytechnic University, Hong Kong. Her current research interests include pattern recognition, image processing, and remote sensing. Dr. Dong is a reviewer of more than twenty international journals, including the IEEE TGRS, TIP, TNNLS, TMM, and PR. E-mail:dongyanni@cug.edu.cn.

Code of State Categories Scientific and Technical Information (in Russian-GRNTI)): 29.31.15, 29.33.43, 20.53.23. Received October 29, 2020. The final version-February 25, 2021. 